\title{
A eutanásia e suas razões
}

\section{Euthanasia and its justifications}

\section{Resumo}

Este trabalho se propõe a analisar as principais razões contrárias à prática da eutanásia. Argumentaremos que estas podem ser resumidas em três ordens principais de considerações: a proteção à pessoa de si mesma; o respeito a valores impessoais, como a sacralidade da vida e a dignidade do agente; o risco de abusos. Em cada um destes casos, procuraremos analisar em que medida tais considerações têm realmente força o suficiente para justificar uma proibição estrita à eutanásia.

Palavras-chave: eutanásia; razões prudenciais; sacralidade da vida; dignidade do agente; ladeira escorregadia.

\begin{abstract}
In this paper I try to analyze the main arguments against the practice of euthanasia. I'll try to show that these can be assembled in three great categories: a-protecting the individual from himself; $b$ - respect for impersonal values, such as the sanctity of life and agent's dignity; c- the risk of abuse. In each case I'll investigate whether those arguments really have the force to justify a strict prohibition of euthanasia.
\end{abstract}

Key words: Euthanasia; prudential reasons; the sanctity of life; the dignity of the agent; slippery slope.

\footnotetext{
* Professor do Departamento de Filosofia da Universidade Federal de Goiás.

E-mail: rafarodrigues252@gmail.com
}

Recebido em: 24/07/2018. Aceito em: 11/08/2019. 


\section{Introdução}

Neste artigo nos propomos a expor um quadro geral do debate sobre a eutanásia, discutindo os principais argumentos contrários à legalização desta prática. Como veremos, há três tipos básicos de oposição: a- porque a morte é sempre ruim para a própria pessoa; b- porque esta prática viola algum valor impessoal; c- porque sua legalização terá um efeito negativo sobre terceiros. Faremos uma análise destas ordens de consideração.

Antes de começarmos, convém lembrar algumas definições gerais. A raiz etimológica do termo eutanásia é "boa morte" (do grego eu, "bom", e tanàtos, "morte"). O sentido atual da palavra, no entanto, é o de uma morte causada por terceiros, em benefício da pessoa que é morta, e realizada com esta intenção. ${ }^{1}$

A partir dessa definição, podemos distinguir algumas categorias.

A eutanásia voluntária ocorre quando uma pessoa pede voluntariamente para ser morta. Como comenta Foot, é preciso considerar que o simples fato de se atender a um pedido deste tipo não basta para caracterizar a eutanásia, pois esta precisa ser feita em benefício da pessoa morta, que, conforme comentaremos a seguir, pode estar equivocada em querer morrer. Não estaremos necessariamente praticando uma eutanásia, por exemplo, se contribuímos para a morte de um adolescente depressivo, somente porque ele nos pediu isso; a eutanásia precisa "de fato" beneficiar a pessoa morta.

A eutanásia não-voluntária ocorre quando a pessoa a ser morta não está em condições de manifestar sua vontade (pacientes em coma, com um retardamento mental sério, um bebê recém- nascido etc).

A eutanásia involuntária ocorre quando a pessoa é morta mesmo após manifestar vontade contrária. Claro que estes casos são raríssimos, embora seja uma possibilidade conceitual. De fato, assim como uma pessoa pode estar enganada em achar que a morte lhe será benéfica, também pode, em circunstâncias atípicas, estar enganada em achar que a morte não é um bem - por exemplo, um homem ferido em um campo de batalha, que não sabe os horrores por que terá que passar se for capturado. ${ }^{2}$

1 Foot, P. Euthanasia. In:

Virtues and Vices and Other Essays in Moral Philosophy. Oxford: Oxford University Press, 2002, p. 34; Cf. McMahan, J. A Ética no Ato de Matar. Porto Alegre: Artmed Editora, 2011, p. 478.

2 É claro que mesmo nos casos em que a morte seja, de fato, boa para uma pessoa, ainda seria contestável que fosse moralmente correto matá-la contra sua vontade. Philippa Foot expressa este ponto a partir de uma distinção entre os requerimentos da caridade, por um lado, e os da 
O suicídio assistido ocorre quando a própria pessoa ocasiona sua morte, mas auxiliada por terceiros.

A eutanásia ativa ocorre quando terceiros ocasionam diretamente a morte de alguém, em benefício desta pessoa.

A eutanásia passiva ocorre quando poderíamos impedir a morte de uma pessoa, mas não o fazemos em seu benefício.

A ortotanásia (etimologicamente "morte correta", na hora certa) é um tipo específico de eutanásia passiva, quando um determinado tratamento é suspenso por sua futilidade em prolongar significativamente a vida do paciente, ou em aliviar seu sofrimento.

Após estas especificações, passaremos à análise da normatividade da eutanásia, ou seja, como esta pode ser justificada. Nossa abordagem será "negativa" na medida em que analisaremos argumentos contrários a esta prática. Conforme já comentamos, são três os principais tipos de argumento:

(a) proteger a pessoa de si mesma (partindo da premissa de que a morte é sempre um mal para ela).

(b) evitar que algum valor impessoal seja violado (como a sacralidade da vida ou a dignidade humana).

(c) evitar efeitos negativos sobre terceiros (risco de abusos).

\section{I - Protegendo a pessoa de si mesma}

A morte pode ser um bem? Esta questão remete, obviamente, à racionalidade do suicídio: pode ser prudencialmente justificado - ou seja, em relação àquilo que é bom para a própria pessoa ${ }^{3}$ - querer pôr fim à própria vida?

justiça, por outro, que pressupõem o respeito aos direitos individuais (Foot, P. Euthanasia. In: Press, 2002, p. 48).

Virtues and Vices and Other Essays in Moral Philosophy. Oxford: Oxford University

3 O suicídio também pode ser criticado a partir de considerações morais, por prejudicar outras pessoas - por exemplo, uma mãe de família que deixa seus filhos desamparados ao se suicidar. Da mesma forma, o suicídio pode, às vezes, ser justificado por questões morais - por exemplo, um agente secreto que se mata para não revelar segredos importantes. Mas aqui estaremos abordando apenas considerações prudenciais, que remetem ao que seria bom para a própria pessoa. 
Uma pessoa pode, é claro, estar equivocada em querer morrer - por estar sob efeito de depressão, por lhe faltar maturidade, por ignorar informações relevantes acerca de sua situação, por se sentir frágil psicologicamente - por exemplo, dificuldade de lidar com alguma pressão - e até mesmo por desvios de caráter, como a covardia. Mas será sempre assim? Não haveria circunstâncias específicas nas quais seja racional para alguém desejar a própria morte?

À primeira vista, pode parecer difícil discutir um tema como esse, pois a noção de felicidade, pelo menos para nós, modernos, tornou-se um tanto o quanto subjetiva (voltaremos a este ponto mais adiante). No entanto, mesmo dentro deste quadro subjetivista, ainda faz sentido considerar que uma pessoa pode estar equivocada em querer se matar, e, portanto, que podemos estar enganados em relação àquilo que é bom para nós. Se este engano é possível, é porque há alguma objetividade aqui, que nos permite discutir esta questão, ainda que, talvez, em termos bastante genéricos.

O que, então, faria uma vida não valer a pena de ser vivida? Segundo McMahan, o suicídio pode ser prudencialmente justificado em vidas "com apenas dor e sofrimento, sem serem enobrecidas por isso". ${ }^{4}$ Philipa Foot considera que a morte pode ser benéfica quando nos faltam determinados "bens básicos" - como, por exemplo, não trabalhar muito além de nossa capacidade, ter suporte da família e da comunidade, satisfazer razoavelmente bem nossa fome, ter lugar para dormir, ter esperanças quanto ao futuro, entre outros. ${ }^{5}$

Em nossa análise, nos concentraremos, sobretudo, em Ronald Dworkin, que propõe, para tratar desta questão, uma interessante distinção entre interesses críticos e experienciais. Segundo Dworkin, interesses experienciais remetem a preferências subjetivas (coisas de que a pessoa gosta de fazer, como viajar, etc), enquanto os interesses críticos remetem a interesses reais das pessoas, coisas que elas devem desejar. Trata-se, assim, de uma distinção entre preferências subjetivas e interesses objetivos. ${ }^{6}$ Dworkin comenta que esta distinção é necessária, por exemplo, para entender por que o uso de drogas pode ser ruim para a própria pessoa, ainda que a experiência, em si, seja agradável. ${ }^{7}$ O ponto, segundo o autor, é que não procuramos apenas ter experiências em

\footnotetext{
4 McMahan, J. A Ética no Ato de Matar. Porto Alegre: Artmed Editora, 2011, p. 479.

5 FOOT, P. Euthanasia. In: Virtues and Vices and Other Essays in Moral Philosophy. Oxford: Oxford University Press, 2002, p. 41.

6 Dworkin, R. O Dominio da Vida. São Paulo: Martins Fontes, 2009, p. 283.

7 Ibidem, p. 286.
} 
nossas vidas, mas também queremos que estas contenham uma estrutura, expressando uma escolha coerente entre estas experiências. ${ }^{8}$

O filósofo americano procura, então, aplicar esta distinção à eutanásia, mostrando como segundo ambos os entendimentos a morte pode ser um bem. De um ponto de vista experiencial, uma pessoa teria boas razões em querer morrer se houver uma perspectiva de grande sofrimento em seu futuro. Podemos pensar, aqui, em pacientes com uma doença terminal dolorosa e incurável. Nossa relação com a morte, no entanto, também pode ser explicada a partir dos interesses críticos. Neste caso, trata-se de pensar o senso de integridade e coerência de nossas vidas, e isto, pode-se argumentar, se liga a nosso "senso de identidade", ou seja, à maneira pela qual compreendemos a nós mesmos. ${ }^{9}$ Imaginemos, por exemplo, uma pessoa que fica tetraplégica após um acidente: teria ela bons motivos para achar que sua vida não vale mais a pena? Isso depende de como esta pessoa compreende "quem" ela é. Alguém com um temperamento mais cerebral, por assim dizer - podemos pensar, por exemplo, no caso do físico Stephen Hawking - pode ter mais chances de levar uma vida satisfatória nessas condições. Mas o que dizer de alguém cuja existência, até então, tinha sido mais corporal, como um atleta? Neste caso, pode ser extremamente difícil para esta pessoa "se reinventar", e ter uma vida tão diferente daquela autocompreensão que sempre experimentou de si mesma. Ela talvez tenha bons motivos para achar que sua vida não vale mais a pena. ${ }^{10}$

O significado da morte para nós, assim, está diretamente relacionado a nosso senso de identidade, que, por sua vez, pode remeter a determinados valores que estruturam nossa vida, àquilo que é importante para nós. ${ }^{11}$ Em determinadas culturas guerreiras, por exemplo, morrer em uma batalha, com

\footnotetext{
8 Ibidem, p. 290.

9 Ibidem, p. 298; p. 299.

10 "The Note" é uma famosa carta de suicídio citada em diversas obras de bioética. O autor, Chris Hill, um jovem australiano que ficou tetraplégico após um acidente de asa-delta, procura justificar sua decisão a partir do contraste entre sua atual situação e a vida extremamente física e ativa que levava antes do acidente (HILL, C. The Note. In: KUHSE, H; SINGER, P. (eds): Bioethics - an anthology. Oxford: Blackwell Publishing, 2006). Também podemos pensar, aqui, em alguns personagens fictícios, como a dançarina Beatriz, em um dos episódios da série Justiça, veiculada pela rede Globo em 2016. Beatriz também ficou tetraplégica, após ser atropelada. Em ambos os casos, a autocompreensão resultante de suas existências passadas torna muito difícil para estas pessoas darem algum sentido a suas vidas após seus respectivos acidentes.
}

11 Charles Taylor é um exemplo de autor que relaciona identidade e valores. Como diz em sua obra As Fontes do Self, "saber quem se é equivale a estar orientado no espaço moral, onde surgem 
honra, seria visto como uma boa morte, o clímax adequado para uma vida de valor. Nos dias atuais, podemos imaginar como uma pessoa que sempre prezou por sua autonomia e independência, descobrindo estar com alguma doença degenerativa, muscular ou cognitiva, considere insuportável a maneira pela qual dependerá cada vez mais dos outros. Decidir quando e como vai morrer pode ser uma maneira, para esta pessoa, de afirmar pela última vez seu controle sobre a própria vida - de morrer, assim, de acordo com os valores pelos quais sempre viveu. Como diz Dworkin, "nenhum de nós quer terminar sua vida em desacordo com os parâmetros que sempre a nortearam". ${ }^{12}$

Claro, muitas vezes a autocompreensão pode nos levar, ao contrário, a lutar contra uma doença e tentar prolongar ao máximo nossa vida - por exemplo, para afirmar nossa autoimagem de pessoa guerreira, lutadora, ou simplesmente porque queremos presenciar algum evento significativo para nós, como o nascimento de um neto. ${ }^{13} \mathrm{O}$ ponto, no entanto, é que nossa relação com a morte reflete nosso senso de identidade, que, por sua vez, é constituído por certos valores. Somos criaturas complexas, para as quais "viver" não é simplesmente "sobreviver", e, neste sentido, nem sempre temos como interesse fundamental sermos mantidos vivos o máximo de tempo possível.

Este ponto remete, a nosso ver, aos diferentes significados que conferimos à noção de vida: quando o problema da eutanásia é abordado do ponto de vista daquilo que seria bom para a própria pessoa - de sua felicidade, por assim dizer -, então a "vida" não pode ser entendida apenas em termos biológicos. Ela também precisa ser compreendida em um sentido que podemos chamar de biográfico. Se a vida fosse um fenômeno meramente biológico, talvez fizesse sentido sempre nos empenharmos para manter um determinado organismo funcionando (à frente, veremos que até mesmo esta posição pode ser problematizada). As pessoas, no entanto, não veem a si mesmas apenas como "organismos", e, portanto, o debate sobre a eutanásia, quando abordado sob o ponto de vista dos valores prudenciais, torna-se bem mais complexo.

Em função desta análise podemos concluir que a primeira ordem de considerações contrária à prática da eutanásia - proteger a pessoa de si mesma, partindo da premissa de que a morte é sempre um mal para ela - não se tido e importância para o indivíduo" (Taylor, C. As Fontes do Self. São Paulo: Loyola, 2010, p. 44).

12 Dworkin, R. O Domínio da Vida. São Paulo: Martins Fontes, 2009, p. 301.

13 Ibidem, p. 299. 
sustenta. A morte, de fato, pode, em algumas circunstâncias, ser benéfica para alguém, do seu próprio ponto de vista, e, portanto, nestes casos, a eutanásia seria justificada, se levarmos em conta apenas critérios prudenciais.

Esta conclusão, no entanto, ainda deixa em aberto um ponto importante, que é o problema do paternalismo. Vimos, de fato, que uma pessoa pode estar equivocada em ver a morte como um bem - não estaremos praticando uma eutanásia justificada se simplesmente atendemos ao pedido de um adolescente suicida. A análise de Dworkin reforça esta dimensão objetiva, pois se por um lado os interesses experienciais são puramente subjetivos (ou gostamos de algo, ou não gostamos), por outro lado podemos sim estar enganados quanto a nossos interesses críticos. No entanto, é claro que a posição da própria pessoa deve ter um peso importante para determinar se a morte é ou não um bem para ela - nossa análise também reforçou este ponto, ao enfatizar a maneira pela qual o significado da morte depende da autocompreensão de cada um.

Esta questão remete a um debate acerca da subjetividade e objetividade dos valores prudenciais na era moderna. Não temos tempo para enveredar, aqui, por esta discussão, que pode se tornar bastante complexa. ${ }^{14}$ Mas vamos tocar neste ponto rapidamente, a partir de um artigo de Richard Kraut, Two Concepts of Happiness. Kraut afirma que o conceito de felicidade sempre envolve tanto elementos subjetivos quanto objetivos: queremos que nossa vida transcorra "de uma determinada maneira" (a estrutura de que fala Dworkin), mas, ao mesmo tempo, o indivíduo deve desejar e apreciar, em nível pessoal, este modo de vida. ${ }^{15}$ Esta combinação de elementos objetivos e subjetivos seria comum tanto à concepção de felicidade dos antigos quanto à dos modernos. A diferença é que para os antigos a ênfase estava na dimensão objetiva: a eudaimonia consistia, assim, em adaptarmos nossos desejos e inclinações a algum padrão externo de boa vida - a vida do guerreiro, do sábio, com prestígio social etc. Na era moderna a noção de felicidade tornou-se mais subjetiva, cada indivíduo tendo, em princípio, a liberdade de viver segundo "sua" própria concepção. Esta dimensão subjetiva não impede, no entanto, que a visão moderna também contenha elementos objetivos - porém mais ligados, podemos dizer, a uma questão de consistência interna, ou, talvez, de

14 Um bom livro que discute tais assuntos é a coletânea editada por Lawrence Jost e Roger Shiner, Eudaimonia and Well-being: Ancient and Modern Conceptions. Cambridge: Academic Printing \& Pub, 2002.

15 Kraut, R. Two Conceptions of Happiness. The Philosophical Review, 88, no 2, 1979, p. 167. 
maturidade, e não a algum padrão externo pré-estabelecido. As concepções modernas de felicidade podem assim ser designadas, segundo Kraut, de subjetivismo moderado. ${ }^{16}$

Podemos considerar que existem duas maneiras de estarmos equivocados em relação a nossos valores prudenciais: primeiro, podemos estar errados em ver algo como um meio de honrar ou de promover tais valores (no caso da eutanásia, por exemplo, pode haver algum exagero em acharmos que insistir em uma batalha já perdida faz de nós algum tipo de guerreiro). Por outro lado, os próprios valores podem estar equivocados. Aqui estaria, como dissemos, a principal diferença entre a visão moderna e a dos antigos, pois para nós este tipo de equívoco não se dá mais em função da inadequação a algum padrão externo. Mas, ainda assim, nos parece aceitável que valores pessoais possam refletir algum tipo de imaturidade ou de ignorância. Hoje em dia não acreditamos mais que uma pessoa só possa ser feliz se, digamos, levar uma vida honrada segundo os padrões da sociedade. Mas, ao mesmo tempo, reconhecemos que estudar exerce alguma influência sobre nossa concepção de felicidade, e que um adolescente estaria equivocado em achar que o fim de um relacionamento amoroso é motivo para querer morrer.

Porém, mesmo com a possibilidade de haver tais equívocos, valores prudenciais são sempre "nossos" em um sentido bem mais forte do que no mundo antigo. Se transpusermos estas reflexões para o debate sobre a eutanásia, podemos afirmar que a posição do próprio indivíduo deve possuir um peso determinante para que o procedimento seja autorizado (se levarmos em consideração, é claro, apenas o critério prudencial que estamos discutindo nesta seção). No entanto, a possibilidade de o indivíduo estar enganado quanto a seu próprio bem permite a imposição de certas condições para esta autorização: por exemplo, um limite de idade, para que se tenha a maturidade necessária na tomada de uma decisão tão difícil; a discussão do assunto de forma exaustiva (não apenas por parte de médicos, mas também de parentes etc), para termos certeza de que a pessoa não está ignorando informações relevantes acerca de sua situação; um exame clínico que ateste que a pessoa não está sob efeito de depressão ou de outros fatores que podem distorcer suas decisões; a certificação da posição mantida pela pessoa durante certo período de tempo, assegurando-se não se tratar de uma decisão apressada (ela pode, de fato, precisar de tempo para se acostumar com sua nova situação). Entre outras condições. 
É claro que nossa exposição se aplica, sobretudo, à eutanásia voluntária, quando o indivíduo está em condições de manifestar sua intenção em morrer. O que dizer quanto à involuntária e à não-voluntária?

As considerações acima colocam limites ainda mais rígidos aos casos - já raríssimos - nos quais a eutanásia involuntária poderia se aplicar. A partir do momento em que consideramos o desejo em querer morrer como uma condição necessária, ainda que não seja suficiente, para determinar o bem de uma pessoa, nunca seria justificado matar alguém contra sua vontade. Em relação à eutanásia não-voluntária, o problema, obviamente, está em não sabermos qual seria o juízo do indivíduo sobre sua própria morte. Em casos em que o indivíduo já pôde, anteriormente, manifestar sua vontade (por exemplo, pessoas em coma após sofrer algum acidente, ou com alguma doença cognitiva degenerativa), podemos tentar inferir sua concepção de bem a partir de coisas que ele tenha dito, escrito, de seu comportamento, enfim, daquilo que sabemos sobre sua personalidade e sobre seus valores. Se este tipo de inferência não for possível (por exemplo, pessoas que já nasceram neste estado), podemos adotar um modelo de considerações sobre "interesses fundamentais", comuns à maioria das pessoas, como aquele proposto por Dworkin. ${ }^{17}$

\section{II - Valores impessoais}

A segunda ordem de considerações contrárias à eutanásia faz referência a algum tipo de valor impessoal. Enquanto na seção anterior analisamos se a morte pode ser um bem para a própria pessoa, estamos agora nos referindo a algo que deve ser valorizado em si mesmo, independentemente da importância que tenha "para" alguém em particular. Segundo esta perspectiva, a eutanásia não seria justificada ainda que o indivíduo tenha bons motivos, de um ponto de vista prudencial, para querer morrer.

Existem dois candidatos principais para valores impessoais no debate filosófico tradicional: a sacralidade da vida e a dignidade do agente. Trataremos de ambos a seguir. No final desta seção também abordaremos a questão da morte como um tabu, pois é muito fácil confundir esta questão com a dos valores impessoais, embora, como veremos, trate-se de algo bem diferente.

17 Dworkin, R. O Domínio da Vida. São Paulo: Martins Fontes, 2009, pp. 271-274. 
a) A sacralidade da vida.

A expressão "sacralidade da vida" faz referência a um valor "da" vida em si mesma, independentemente, portanto, de sua importância para quem a vive. Como diz Dworkin, trata-se da distinção entre considerar que manter uma pessoa viva é bom para ela mesma e que esta decisão respeita um valor incorporado a esta vida. ${ }^{18}$

Esta expressão nos faz pensar, de forma mais imediata, em considerações religiosas. Trataremos, assim, inicialmente, desta perspectiva, mas, posteriormente, comentaremos como é possível sustentar esta noção a partir de um ponto de vista secular.

Existe uma grande variedade de posições religiosas, não somente entre as principais doutrinas (catolicismo, islamismo, judaísmo etc), mas, também, muitas vezes, entres correntes internas a cada uma delas. Iremos, aqui, nos concentrar no catolicismo - a principal referência em debates religiosos sobre o valor da vida no ocidente -, e, de forma mais específica, na posição oficial defendida pelo Vaticano.

A posição oficial do Vaticano quanto à sacralidade da vida está exposta na Congregação para a Doutrina da Fé, documento elaborado durante a gestão do Papa João Paulo II, em 1988. Segue um trecho deste documento:

A vida humana é sagrada porque desde o seu início comporta « a ação criadora de Deus » e permanece para sempre em uma relação especial com o Criador, seu único fim. Somente Deus é o Senhor da vida, desde o seu início até o seu fim: ninguém, em nenhuma circunstância, pode reivindicar para si o direito de destruir diretamente um ser humano inocente. ${ }^{19}$

A "sacralidade da vida", assim, é derivada da relação especial que existe entre o homem e seu criador. ${ }^{20}$ A vida deve ser entendida como um presente de Deus. Esta noção, aqui, envolve a posse de uma alma, ou seja, não pode ser entendida em um sentido puramente biológico. E esta alma, que confere ao ser humano seu estatuto especial, estaria presente desde a concepção.

18 Ibidem, p. 303.

19 Sagrada Congregação Para a Doutrina da Fé, Donum Vitae, introdução - 5.

20 Neste sentido trata-se, como comenta ironicamente Singer, da sacralidade da vida humana, e não "da" vida de forma geral (Singer, P. Ética Prática. São Paulo: Martins Fontes, 2002, pp. 93-94). 
Esta tese pode ser interpretada de duas maneiras: em primeiro lugar, podemos considerar que a origem divina confere à vida humana um valor intrínseco extremamente importante. É a maior dádiva ofertada por Deus. Este valor é tão alto que tende a se sobrepor a qualquer outra ordem de considerações - como, por exemplo, a felicidade pessoal -, o que significa, assim, que em nenhuma circunstância - ou em raríssimas - a destruição de uma vida humana pode ser justificada.

No entanto, também é possível interpretar a posição do Vaticano a partir do paradigma dos direitos: a origem divina não apenas confere à vida dos humanos um valor muito alto, como também os torna sujeitos de direitos. Ao matar uma pessoa, assim, estamos violando seu direito à vida. ${ }^{21} \mathrm{O}$ curioso, é claro, é que isso aconteceria ainda que a pessoa em questão queira morrer. É possível, de fato, defender que o direito à vida é violado somente em situações nas quais pessoas sejam mortas contra sua vontade - em outras palavras, que um indivíduo possa, caso queira, renunciar a esta prerrogativa. ${ }^{22}$ Posições religiosas, no entanto, tendem a sustentar que as pessoas não podem abrir mão de seu direito à vida - exatamente pelo fato de ser uma dádiva de Deus, que não pode ser recusada.

Segundo esta perspectiva, assim, não é justificável para alguém pôr fim à própria vida, nem terceiros contribuírem para isso, ainda que esta pessoa tenha bons motivos, em termos prudenciais, para querer morrer. Ela deve, portanto, suportar qualquer sofrimento que o mundo lhe trouxer, em respeito ao valor sagrado, impessoal, da vida humana. ${ }^{23}$

21 Diversos trechos do documento oficial do Vaticano, de fato, falam em direito à vida: "O ser humano deve ser respeitado e tratado como pessoa desde a sua concepção e, por isso, desde aquele mesmo momento devem ser-lhe reconhecidos os direitos da pessoa, entre os quais, antes de tudo, o direito inviolável de cada ser humano inocente à vida" (Sagrada Congregação Para a Doutrina da Fé, Donum Vitae, I-1).

22 Cf. Singer, P. Ética Prática. São Paulo: Martins Fontes, 2002, p. 205.

23 "Pode acontecer que dores prolongadas e insuportáveis, razões de ordem afetiva ou vários outros motivos, levem alguém a julgar que pode legitimamente pedir a morte para si ou dá-la a outros. Embora em tais casos a responsabilidade possa ficar atenuada ou até não existir, o erro de juízo da consciência - mesmo de boa-fé - não modifica a natureza deste gesto homicida que, em si, permanece sempre inaceitável" (Sagrada Congregação Para a Doutrina da Fé, Declaração Sobre a Eutanásia, seção II) 
O principal problema em se defender a sacralidade da vida nestes termos está, obviamente, no fato de que tal posição depende de crenças específicas, sobretudo sobre a existência de Deus. ${ }^{24}$ Pode-se questionar, assim, que a proibição da eutanásia possa se basear neste tipo de consideração em sociedades seculares, onde há separação entre Igreja e Estado.

É possível, no entanto, falar da santidade da vida de forma secular. Talvez a principal referência deste tipo de posição seja, mais uma vez, Ronald Dworkin. Como veremos, em uma perspectiva secular não é tão óbvio que a eutanásia seja uma afronta à santidade da vida.

Dworkin considera que há três tipos de valor que podem ser atribuídos a alguma coisa: um valor instrumental, um valor subjetivo, e um valor intrínseco. Neste último caso tratamos algo como tendo valor em si mesmo, independentemente do que as pessoas precisam, desejam ou apreciam. $.^{25} \mathrm{Va}-$ lores intrínsecos, por sua vez, podem ser distinguidos em incrementais (que devem ser maximizados) e o valor "sagrado", que deve ser respeitado. ${ }^{26}$ Há duas maneiras de atribuir um valor sagrado a alguma coisa: por associação (por exemplo, o valor de um símbolo, como uma bandeira), ou a partir da sua gênese, ou seja, devido ao modo como algo veio a existir: "a essência do sagrado está no valor que atribuímos a um processo, empreendimento ou projeto, e não a seus resultados considerados independentemente do modo como foram obtidos". ${ }^{27}$ Esta seria a maneira pela qual atribuímos valor intrínseco a uma determinada espécie animal, por exemplo, ou a uma obra de arte: ficamos horrorizados com a possibilidade de seu desaparecimento, devido ao profundo respeito que temos pelos empreendimentos - sejam estes humanos ou naturais - que lhe deram origem. ${ }^{28}$

Segundo esta perspectiva, o valor sagrado da vida pode ser compreendido de duas maneiras, dependendo do tipo de gênese que lhe atribuímos: o natural ou o cultural. $\mathrm{O}$ autor faz uma interessante ilustração desta distinção a

24 Singer comenta, neste sentido, que a vida humana claramente não era considerada sagrada, por exemplo, na cultura greco-romana, e que nossas atitudes atuais quanto a este ponto "remontam ao advento do cristianismo" (Singer, P. Ética Prática. São Paulo: Martins Fontes, 2002, pp. 98-99).

25 Dworkin, R. O Dominio da Vida. São Paulo: Martins Fontes, 2009, p. 99.

26 Este termo está sendo utiizado aqui, portanto, em um sentido mais técnico, desprovido de suas conotações religiosas habituais.

27 Dworkin, R. O Domínio da Vida. São Paulo: Martins Fontes, 2009, p. 109.

28 Ibidem, p. 109. 
partir dos termos usados pelos gregos para falar da vida: zoe, para designar a dimensão biológica, e bios, para tratar da vida como processo vivido, o conjunto de ações, decisões, motivos e acontecimentos que compõe o que hoje chamaríamos de biografia. ${ }^{29}$ Reencontramos, assim, os dois significados da vida de que tratamos rapidamente na seção anterior: o biológico e o biográfico. A estes podemos acrescentar, agora, um terceiro significado, o religioso. A abordagem de Dworkin mostra que a vida pode ser considerada "sagrada" nos três sentidos, com consequências diferentes para o debate sobre a eutanásia.

A compreensão religiosa tende a sustentar, como vimos, uma posição contrária à eutanásia. Será que o mesmo ocorre com o sentido biológico e com a biográfico? À primeira vista, conforme já comentamos, a perspectiva biológica também levaria a uma posição contrária. O respeito à santidade da vida, entendida desta maneira, é o que levaria os médicos, por exemplo, a procurar manter nosso organismo funcionando a todo custo. Dworkin, no entanto, considera ser possível interpretar esta dimensão de forma a sustentar uma posição favorável à eutanásia. De fato, se a vida humana for compreendida como um investimento da natureza, pode-se discordar de que a morte biológica sempre frustre este valor.

Podemos, plausivelmente, acreditar que prolongar a vida de uma pessoa muito doente, ou que já perdeu a consciência, em nada contribui para concretizar a maravilha natural da vida humana, e que os objetivos da natureza não são atendidos quando os artefatos de plástico, a sucção respiratória e a química mantêm o coração batendo em um corpo inerte e sem mente, um coração que a própria natureza já teria feito calar-se. ${ }^{30}$

E quanto à dimensão biográfica? Na primeira seção, quando falamos da felicidade, este sentido foi entendido em função do que seria o bem para a própria pessoa. Uma biografia, porém, também pode incorporar um valor impessoal, que deve ser respeitado independentemente dos interesses particulares de alguém. Segundo esta perspectiva, devemos tratar nossa própria existência, como diz Dworkin, "como algo sagrado pelo qual somos responsáveis, algo que não podemos pôr a perder". ${ }^{31}$

29 Ibidem, p. 115

30 Ibidem, p. 304.

31 Ibidem, pp. 304-305 
Se a vida for compreendida a partir desta dimensão, torna-se ainda mais fácil negar que a eutanásia insulte sua santidade. ${ }^{32}$ Este tipo de investimento, de fato, está estreitamente ligado à ideia de que nossa vida se desenvolva bem, e, portanto, estará sendo frustrado se esta existência se encontrar em um estado degradante, a ponto de não valer mais a pena de ser vivida. É claro que também posso respeitar o valor da vida me agarrando a ela com todas as forças, lutando bravamente contra alguma doença. Este tipo de batalha pode contribuir para fazer de nossa existência uma bela história. Mas nem sempre é assim - às vezes, um estado degradante é apenas degradante, e nossa bios ficará manchada, por assim dizer, se formos submetidos àquela situação aviltante. Como diz Velleman, destruir alguma coisa pode ser, às vezes, a melhor maneira de preservar seu valor, ao impedir que este se deteriore. ${ }^{33}$

Podemos assim concluir que o papel exercido pela "sacralidade da vida" no debate sobre a eutanásia dependerá de como a noção de vida é compreendida. Vimos, anteriormente, três formas diferentes de articular esta noção: como uma dádiva de Deus, como um fenômeno natural ou como um fenômeno cultural. A forte conotação religiosa que costumamos atribuir ao "sagrado" contribui para que a eutanásia seja considerada, em geral, como uma violação deste valor. Procuramos argumentar, no entanto, que encurtar uma existência degradante, ou em processo de degradação, também pode ser uma maneira de respeitar a santidade da vida, se entendida de forma secular.

Como veremos a seguir, a mesma ambivalência aparece quando discutimos a noção de dignidade.

b) A dignidade do agente.

Enquanto a noção de sacralidade, abordada na seção anterior, era atribuída à vida humana, a base da dignidade são as próprias pessoas. Trata-se de um valor "do" indivíduo, que não depende da importância deste para alguém, o que inclui - e este será um ponto importante - para o próprio indivíduo em questão. Segundo esta perspectiva, as pessoas possuem um valor enquanto pessoas, que é diferente daquilo que é bom para elas. 
A principal referência deste tipo de concepção é Kant. $O$ filósofo alemão concebia a dignidade (Wurde) como um valor intrínseco inerente a todos os agentes racionais, em oposição a "preço" (Preis), que seria um valor relacional atribuído a objetos. A dignidade assegura aos agentes uma prerrogativa de serem respeitados enquanto sujeitos, o que significa, na teoria de Kant, que devem ser tratados como fins em si mesmos, e não como meros instrumentos a serviço da vontade de alguém. ${ }^{34}$

Embora Kant não tenha abordado diretamente a questão da eutanásia, podemos inferir sua posição sobre este tema a partir de suas asserções acerca do suicídio. Kant considerava o suicídio imoral porque consistiria em uma violação, por parte do agente, de sua própria dignidade. Este ponto se liga a uma característica central da ética kantiana, que é a independência entre moralidade e felicidade: razões morais e razões prudenciais correspondem a ordens de consideração de origens diferentes e incomensuráveis. ${ }^{35}$ Em certas situações podemos ter razões morais para preferir a morte - por exemplo, quando nos sacrificamos para defender pessoas inocentes. As razões do suicida, no entanto, sempre terão por origem sua concepção subjetiva de felicidade. Ao tratar seu valor enquanto agente racional como algo que seria comensurável com aquilo que é bom "para" ele, este agente estaria, assim, instrumentalizando a si mesmo em função de seus objetivos pessoais. Isso significa, na perspectiva de Kant, que o suicida atenta contra a própria dignidade. A concepção do filósofo alemão, neste ponto, lembra aquilo que vimos, anteriormente, acerca da visão católica sobre a sacralidade da vida: o agente expressa sua dignidade através da capacidade de suportar, de cabeça erguida, os maiores infortúnios que a vida lhe trouxer.

Enquanto a origem do valor sagrado da vida estaria, como vimos, em algum investimento divino, natural ou cultural, a dignidade repousa em certas capacidades psicológicas do agente. ${ }^{36}$ No caso específico da concepção de Kant, trata-se da capacidade para a moralidade - ou seja, para a autonomia, enquanto poder dos agentes racionais de se autodeterminarem a partir da razão prática pura. Independentemente da concepção que se tenha das faculdades envolvidas, esta referência gera um tipo de problema que a noção de sacralidade parecia evitar: o estatuto de indivíduos que não tenham as

34 Kant, I. Fundamentação da Metafísica dos Costumes. Lisboa: Edições 70, 2011, p. 73; p. 82.

35 Concepções de felicidade dependem de inclinações do agente, enquanto a moralidade é derivada da razão prática pura (Ibidem, pp. 92-97).

36 McMahan, J. A Ética no Ato de Matar. Porto Alegre: Artmed Editora, 2011, p. 494. 
capacidades requeridas. Podemos pensar, de forma mais imediata, em animais não-humanos (que para Kant não eram sujeitos, mais sim objetos ${ }^{37}$ ), mas também em seres humanos com as capacidades cognitivas reduzidas, como recém-nascidos, pessoas em coma ou com algum tipo de retardamento. Estes indivíduos não possuem uma dignidade que deva ser respeitada? Não temos espaço para adentrar nesta discussão aqui, embora toquemos neste assunto rapidamente, mais adiante, quando falarmos da eutanásia não-voluntária.

A posição de Kant reflete, grosso modo, a maneira pela qual a dignidade costuma ser abordada dentro da tradição filosófica. O ponto que gostaríamos de discutir, no entanto, é o de que, assim como ocorreu com a santidade, a noção de dignidade também pode ser retrabalhada para sustentar uma posição favorável à eutanásia. O que precisa ser esclarecido é em que medida ajudar alguém a morrer por seu próprio bem pode ser compatível, e até requerido, pelo respeito por seu valor enquanto pessoa. A dignidade é violada quando um indivíduo que importa de forma singular é tratado de uma maneira não condizente com este estatuto especial; mas será o que sempre acontece quando este indivíduo é morto? O respeito por sua dignidade implica sempre esforçarmo-nos ao máximo para mantê-lo existindo, ainda que o próprio indivíduo não queira mais isso, e sua vida claramente não valha mais a pena ser vivida? ${ }^{38}$

É interessante observar que assim como ocorreu em nossa exposição acerca da sacralidade da vida, cujo significado depende, como vimos, do que entendemos por "vida", a discussão acerca da dignidade também dependerá do que entendemos por "pessoa". De fato, se a concepção de indivíduo envolvida for muito distante da maneira pela qual nos compreendemos no dia a dia, isso pode acabar gerando um problema de alienação, em que nos sentiremos instrumentalizados por nossa dignidade - o que é, obviamente, um contrassenso. Esta é a linha da crítica de McMahan a Kant: o filósofo americano comenta que para Kant a natureza racional de uma pessoa consiste em seu "eu próprio". ${ }^{39}$ No entanto, segundo McMahan, o verdadeiro objeto do respeito é a pessoa, e esta é mais do que sua natureza racional. Ainda que a capacidade para a racionalidade seja um componente importante da base psicológica que confere dignidade, é possível afirmar que a pessoa importa porque tem uma

37 Kant, I. We Have No Duties to Animals. In: SHAFER-LANDAU, R. Ethical Theory - an anthology. Oxford: Wiley-Blackwell, 2013, pp. 359-360.

38 McMahan, J. A Ética no Ato de Matar. Porto Alegre: Artmed Editora, 2011, p. 497-498.

39 Ibidem, p. 501. 
natureza racional, e isto é diferente de dizer que "a natureza racional é o que importa". ${ }^{40}$ A posição kantiana, assim, envolveria, paradoxalmente, um tipo de instrumentalização do sujeito, na medida em que este se tornaria apenas uma carcaça para sua natureza racional. Se uma pessoa quisesse desesperadamente morrer, e ouvisse de um kantiano que ela não deve sacrificar sua natureza racional em vista de seu próprio bem, ela poderia concluir que é apenas um meio para a preservação desta natureza. ${ }^{41}$

O problema da alienação de si mesmo, apontado por McMahan, remete, a nosso ver, a uma discussão sobre quais são as propriedades psicológicas que servem de base para a dignidade. Vimos que para Kant somente agentes morais são fins intrínsecos, e este estatuto depende, portanto, da sua capacidade de se autodeterminarem independentemente de suas inclinações. Isso significa que a racionalidade prudencial, ligada a nossa busca pela felicidade, não é a fonte de nossa dignidade. Podemos questionar, no entanto, em que medida o critério kantiano não é demasiado exigente. De fato, se nossa capacidade de ter uma concepção de bem e persegui-lo também fizer parte da base psicológica da dignidade, então contribuir para o bem de um indivíduo poderá fazer parte do respeito por ele enquanto indivíduo.

Se atentarmos para o sentido mais comum que costuma ser atribuído à noção de autonomia (inclusive no meio jurídico), veremos que este é um sentido mais fraco do que o kantiano. De fato, consideramos, em geral, que respeitar a autonomia de uma pessoa também consiste em respeitar suas escolhas prudenciais. Como diz McMahan, a deferência adequada ao valor de um indivíduo pode consistir no reconhecimento apropriado de que seu bem é importante, e, portanto, demonstramos respeito pela pessoa quando contribuímos para este bem. Isto ocorreria sobretudo naqueles casos em que o bem em questão corresponde àquilo que o indivíduo quer de forma autônoma. ${ }^{42}$ Nestes casos, de fato, não haveria oposição entre felicidade e autonomia (se esta for entendida em um sentido mais fraco do que o kantiano), e não faria sentido, portanto, considerar que estamos dando prioridade a seu bem em detrimento de sua dignidade. McMahan deixa claro que isso não significa que a distinção entre a dignidade e o bem de uma pessoa foi desfeita. O indivíduo ainda possui um valor enquanto indivíduo. O bem da pessoa importa, nesta perspectiva, porque

\footnotetext{
40 Ibidem, p. 501.

41 Ibidem, p. 501.

42 Ibidem, p. 504
} 
a pessoa importa, e, portanto, o respeito por este bem se torna pelo menos parte daquilo que é exigido por sua dignidade. ${ }^{43}$ Estes dois aspectos tendem a caminhar juntos a partir do momento em que consideramos que a dignidade do agente também tem por base sua racionalidade prudencial. ${ }^{44}$

Segundo esta perspectiva o respeito à dignidade passaria a sustentar, pelo menos em alguns casos, uma posição favorável à eutanásia: um estado irremediavelmente degradante seria um insulto à dignidade de uma pessoa, sobretudo quando esta opta voluntariamente pela morte. ${ }^{45}$ Como dissemos, esta compreensão se harmoniza melhor com a maneira pela qual esta noção costuma ser empregada em nosso dia a dia: quando dizemos, por exemplo, que as pessoas merecem ter uma "vida digna", a dignidade claramente não está sendo entendida, aqui, de uma maneira que independe da felicidade.

Concluindo, podemos afirmar que o papel que a noção de dignidade exercerá no debate sobre a eutanásia dependerá do que entendemos por "indivíduo". Se considerarmos que a capacidade de ter uma concepção de bem e persegui-lo faz parte da base psicológica que confere dignidade - em suma, faz parte daquilo que nos torna pessoas, ou agentes racionais -, então o respeito pela dignidade envolverá um respeito pelas escolhas prudenciais

\section{Ibidem, p. 504.}

44 É claro que seria problemático a base da dignidade ser apenas a racionalidade prudencial, independentemente da moralidade - o que ocorreria, por exemplo, se a concepção de bem de alguém envolvesse matar judeus? Será que deveríamos tolerar esta concepção como parte do respeito pela dignidade desta pessoa? Podemos, é claro, considerar que quando um agente está prudencialmente equivocado, o respeito por sua natureza racional se expressa em um esforço para corrigir seus erros, e não em aceita-los. O ponto, no entanto, é que na visão moderna não fica claro em que medida atos imorais podem ser vistos como erros prudenciais. No mundo antigo, seria possível afirmar que a imoralidade é fruto de uma concepção equivocada de boa vida - tal indivíduo não seria "sábio", como eles diziam. Este tipo de estratégia, no entanto, pressupõe uma objetividade forte dos valores prudenciais. Na visão moderna, caracterizada, como vimos, por um subjetivismo moderado, isso não funciona, pois, embora ainda seja possível falar de equívocos prudenciais, estes não englobam a imoralidade. Neste sentido é que precisamos, no mundo atual, de uma distinção entre razão prudencial e razões morais, e podemos considerar que é esta a ideia de fundo por trás da posição de Kant. É possível, no entanto, como dissemos, amenizar esta posição, considerando que o respeito à dignidade também tem por base a racionalidade prudencial, além da moralidade. Rawls, por exemplo, afirma que a personalidade moral é formada por duas capacidades, o senso de justiça e a de termos uma concepção de bem (Rawls, J. A Theory of Justice - revised edition. Cambridge: Harvard University Press, 1999, § 77, p. 442). Desta forma, a deferência às escolhas prudenciais de uma pessoa fará parte do respeito por sua dignidade, desde que estas escolhas não envolvam atos imorais. No caso da eutanásia, seria preciso, obviamente, defender uma concepção normativa diferente da de Kant, para que o suicídio não seja visto como um ato imoral. Mas isso não é muito difícil de sustentar, na medida em que se trata de uma ação que em geral não envolve danos a terceiros.

45 McMahan, J. A Ética no Ato de Matar. Porto Alegre: Artmed Editora, 2011, p. 498. 
do agente. Isso não significa, como dissemos, que a distinção entre dignidade e felicidade tenha sido desfeita - o indivíduo ainda é respeitado de forma impessoal, enquanto indivíduo. O ponto, justamente, é o que entendemos por "indivíduo".

E quanto à eutanásia involuntária e à não-voluntária? Em relação ao primeiro caso, embora o respeito pela capacidade racional de uma pessoa envolva, muitas vezes, discordar dela e procurar corrigir seus erros, isso deve sempre ocorrer por meio da persuasão, nunca pela força. Obrigar alguém a fazer algo contra sua vontade sempre será um desrespeito a sua dignidade enquanto agente racional (sobretudo em casos tão extremos, que envolvem a morte do agente). Em relação à eutanásia não-voluntária, trata-se do problema, já mencionado, daqueles seres humanos que não possuem as capacidades psicológicas básicas que conferem dignidade - pessoas em coma, com retardamento sério, recém-nascidos etc. Neste caso, podemos tentar lhe conferir dignidade de uma forma indireta - por exemplo, pelo fato de pertencerem à comunidade humana, cujos membros normalmente possuem tal capacidade. Esta comunidade pode ser entendida como espécie biológica ou como algum tipo de comunidade moral. ${ }^{46}$ Outra possibilidade é simplesmente negar que estes seres humanos possuam dignidade, e considerar que questões de vida e de morte, nestes casos, precisam ser trabalhadas a partir de outros tipos de consideração, como a linguagem dos interesses básicos, a dimensão sagrada da vida, ou os danos a terceiros.

\section{c) A morte como um tabu.}

Segundo McMahan, tratar a morte como um "tabu" consiste em considerar a proibição de matar como uma regra desconectada de suas justificativas. A asserção "é errado matar" torna-se tão óbvia que não sentimos mais a necessidade de nos lembrarmos de por que é assim. Isso impede que reconheçamos situações incomuns que configuram exceções a esta regra.

Naturalmente, é desejável que todos nós sejamos profundamente avessos a matar outros seres humanos, e que esta aversão seja diligentemente inculcada como um elemento fundamental da educação moral das pessoas. Mas 
esta aversão deve manter a sua ancoragem nas razões que temos para nos abster de matar; ela não deve se degenerar, transformando-se em um melindre indiscriminado. ${ }^{47}$

A proibição em matar é, obviamente, um princípio fundamental em qualquer sociedade. Porém, até mesmo preceitos desta importância precisam de alguma justificativa que se expresse em razões. Se soubermos quais são estas justificativas, seremos capazes de reconhecer casos atípicos em que aquela proibição não se aplica. Por exemplo, se matar alguém for errado porque isso é ruim para a própria pessoa, então não o será em uma situação em que a morte é um bem para ela. Se for errado em função do respeito que devemos às pessoas, então não o será em casos nos quais matar alguém seja compatível com este respeito. Por outro lado, se a origem do erro está no fato de a vida ser uma dádiva de Deus, então somente Deus pode determinar quando uma pessoa deve ser morta.

É claro que em uma determinada cultura a origem destes preceitos é complexa. Existem, na verdade, diversas origens, com diferentes raízes históricas, que confluem para a proibição. Ainda assim, refletir sobre estas origens pode nos fazer rever o peso relativo que atribuímos a cada uma delas, e identificar com mais facilidade, como dissemos, casos que configurem exceções.

A deferência à regra de "não matar", assim, pode lembrar, à primeira vista, o tipo de respeito suscitado por valores impessoais, como os da sacralidade da vida e da dignidade do agente. Vimos, no entanto, que quando a regra perde contato com as razões que a sustentam ela se torna um tabu, e o respeito por ela, neste caso, torna-se algo diferente, uma espécie de aquiescência não pensada. Como se um princípio fosse melhor cumprido quando não o compreendemos.

\section{III - Danos a terceiros}

O ponto com que finalizamos a seção anterior, a morte como um tabu, remete à terceira ordem de considerações contra a eutanásia: os danos a terceiros. É possível considerar, de fato, que ainda que seja possível reconhecer casos específicos que configurem uma exceção à regra de não matar, este reconhecimento teria como efeito enfraquecer o princípio, gerando, com isso, o risco 
de abusos. A partir do momento em que foi dada esta abertura, quem garante que as exceções serão sempre corretamente identificadas? É razoável supor que haverá equívocos, causados tanto por alguma deficiência de entendimento quanto por má-fé - como, por exemplo, casos em que um idoso doente sofrerá pressão de sua família para optar pela eutanásia.

Trata-se de um tipo de problema chamado, na teoria ética, de "ladeira escorregadia" (slippery slope). É muito comum, por exemplo, opositores à eutanásia apontarem as práticas dos nazistas como um exemplo deste tipo de risco. Os nazistas teriam inicialmente eliminado a vida de pessoas gravemente doentes, de uma maneira que poderia parecer, à primeira vista, aceitável, e a ampliação gradual da esfera de indivíduos implicados teria sido um dos fatores que levaram ao holocausto.

Legalizar a eutanásia equivaleria a colocar uma arma por demais perigosa nas mãos do Estado, ou de indivíduos inescrupulosos e ignorantes. Não é preciso voltar muito atrás na História para se saber dos crimes que poderiam ser cometidos, se a eutanásia fosse legalizada. ${ }^{48}$

Em outras palavras, o problema é em que medida será sempre possível diferenciar a eutanásia de um assassinato. É neste sentido que a legalização desta prática corre o risco de prejudicar terceiros: nas seções anteriores focamos casos em que a eutanásia seria legítima; porém o ponto, agora, é em que medida tais casos contribuirão para que outras pessoas sejam assassinadas sob pretexto de estarem passando por uma eutanásia. Este problema aponta, assim, para uma vantagem de a morte ser tratada como um tabu: a obediência irrestrita a esta regra pode ser injusta em situações específicas que configurariam exceções, mas isto seria compensado pela necessidade de evitar assassinatos que decorreriam da flexibilização do princípio.

Seria esta preocupação legítima? Teria força suficiente para justificar a proibição da eutanásia? Trata-se de um ponto difícil de abordar, pois depende de especulações sobre fatos empíricos. Por conta disso não poderemos desenvolvê-lo tanto quanto fizemos com as considerações anteriores. Mas trataremos rapidamente deste assunto a partir de dois autores que sustentam posições divergentes sobre o tema: Peter Singer e Philippa Foot.

48 Lorber, J. Ethical issues in the management of myelomeningocele and hydrocefalus. Journal of the Royal College of Physicians of London, 10, 1, 1975, p. 204, apud Singer, P. Ética Prática. São Paulo: Martins Fontes, 2002, p. 223. 
Foot classifica o risco de abusos como "a really serious problem". ${ }^{49}$ Ela comenta que muitas pessoas querem "se livrar de outras", e pode ser difícil distinguir casos autênticos de eutanásia daqueles em que a morte foi ocasionada em benefício de terceiros..$^{50}$ Ela chega a citar, justamente, o programa de eutanásia de Hitler, que levou à morte de 275.000 pessoas, e comenta que "talvez seja da mais alta importância manter uma barreira psicológica contra $\mathrm{o}$ ato de matar". ${ }^{51}$ Mesmo em casos de eutanásia voluntária, segundo Foot, não seria fácil elaborar procedimentos que protejam as pessoas de serem persuadidas a dar seu consentimento. ${ }^{52}$ Além disso, as eutanásias voluntárias, ainda que legítimas em alguns casos, podem ter um efeito cultural negativo, afetando, por exemplo, a expectativa social de que pessoas idosas ou doentes sejam amparadas e cuidadas - pode haver uma pressão crescente para que indivíduos nessa situação optem pela eutanásia, o que seria, nas palavras de Foot, um "desastre espiritual" para muitas sociedades..$^{53}$

Foot, no entanto, não indica que estas considerações justifiquem uma proibição radical da eutanásia, mas sim sua restrição a acordos particulares entre pacientes e médicos, no caso de doenças terminais que envolvam muito sofrimento ou incapacidade. O risco real estaria em legalizar esta prática de forma mais ampla, em grande escala. ${ }^{54}$

Peter Singer, por outro lado, se baseia em análises históricas para contestar a força do argumento da ladeira escorregadia. Comenta, por exemplo, que em sociedades que praticavam a eutanásia, como a de Esparta no mundo antigo ou a dos esquimós, isso não levou a nenhum tipo de descontrole em relação a assassinatos.

49 FOOT, P. Euthanasia. In: Oxford: Oxford University Press, 2002, p. 111. Virtues and Vices and Other Essays in Moral Philosophy.

50 Ibidem, p. 111. Foot também considera possível haver um outro tipo de abuso, ligado à eutanásia involuntária: atos que caracterizariam uma eutanásia legítima, no sentido estrito do termo (ou seja, que beneficiariam de fato o indivíduo morto), mas que seriam, ainda assim, um tipo de abuso por serem realizadas contra a vontade do paciente, violando, portanto, os seus direitos (Ibidem, p. 111).

51 Ibidem, p. 112.

52 Ibidem, p. 112.

53 Ibidem, p. 112.

54 Ibidem, p. 111; p. 112. 
Se estas sociedades eram capazes de separar os seres humanos em categorias diferentes, sem transferir suas atitudes de um grupo para outro, nós, com nossos sistemas jurídicos mais sofisticados e o nosso maior conhecimento médico, deveríamos ser capazes de fazer o mesmo. ${ }^{55}$

Em relação aos nazistas, Singer comenta que a comparação é despropositada, pois os nazistas nunca praticaram a eutanásia em seu sentido estrito: desde o início a preocupação não era acabar com o sofrimento das pessoas mortas. ${ }^{56} \mathrm{O}$ ponto de Singer, assim, parece ser o de que as motivações por traz da eutanásia e do assassinato são tão diferentes - opostas, na verdade - que não deveria ser tão difícil diferenciá-los. Casos em que haja um risco real de abuso - por exemplo, idosos sofrerem pressão da família - podem ser amenizados se o processo de autorização da eutanásia for rigoroso, incorporando condições como as que mencionamos na primeira seção. Talvez não seja possível eliminar completamente o risco de distorções, mas este pode ser reduzido até um nível similar ao que ocorre com outras práticas legalizadas, como a doação de órgãos e o uso de próteses, ou mortes indevidas causadas por policiais.

Como dissemos, trata-se de um ponto difícil, pois depende de especulações do tipo "o que aconteceria se...". E estas especulações podem apontar, inclusive, para importantes variações em termos de contextos históricos e culturais: o risco de abuso pode ser maior em determinadas épocas e sociedades, e menor em outras.

\section{Conclusão}

Neste trabalho procuramos analisar os três principais tipos de consideração contra a legalização da eutanásia: razões prudenciais, valores impessoais e o risco de abusos.

55 Singer, P. Ética Prática. São Paulo: Martins Fontes, 2002, p. 227.

56 Ibidem, p. 225. Foot concorda com Singer neste ponto. O programa de Hitler se baseava em uma má compreensão do termo "eutanásia", entendido apenas como uma "morte sem dor", negligenciado, assim, o elemento central de sua definição, o de que deve ser feita em benefício da pessoa morta (FOOT, P. Euthanasia. In: Virtues and Vices and Other Essays in Moral Philosophy. Oxford: Oxford University Press, 2002, p. 34). A filósofa americana, porém, leva mais a sério do que Singer a possibilidade de este tipo de abuso, baseado em uma distorção do sentido do termo, se repetir. 
Nos dois primeiros casos, vimos que estas considerações não parecem sustentar uma proibição estrita da eutanásia, embora possam fundamentar certas restrições. Se compreendemos melhor a maneira pela qual criaturas complexas como nós estruturam sua concepção de "felicidade", vemos que não faz sentido pressupor que a morte sempre consiste em um mal de um ponto de vista prudencial. No entanto, a possibilidade de estarmos equivocados quanto a nosso próprio bem justifica que certas condições sejam impostas à autorização de uma eutanásia.

Em relação aos valores impessoais, vimos que tanto a noção da sacralidade da vida quanto a da dignidade do agente dependem, respectivamente, do que entendemos por "vida" e por "indivíduo". Argumentamos que é possível articular tais noções de forma a sustentar uma posição favorável à eutanásia. É interessante observar que as interpretações tradicionais destes conceitos, que seriam hostis a esta prática, trazem consigo, em geral, pressupostos metafísicos pesados, como a existência de Deus ou o eu numênico kantiano. A interpretação que propomos, assim, parece estar mais de acordo com culturas contemporâneas secularizadas, que buscam seus pressupostos em elementos mais simples do dia a dia.

Em relação à terceira ordem de considerações, o risco de abusos, vimos que há diferentes posições sobre a dimensão que estes abusos podem adquirir. Conforme argumentamos, diversas práticas legalizadas também estão sujeitas a este tipo de risco, como casos de assassinatos cometidos por policiais ou escândalos envolvendo doações de órgãos. As medidas restritivas, nestes casos, passam por um processo mais rigoroso de fiscalização. Muitos argumentam que as consequências da legalização da eutanásia iriam bem mais longe, contribuindo para mudanças negativas em nossa cultura democrática. Como dissemos, é difícil avaliar o grau de correção destas especulações.

O interesse em realizar uma análise como a que fizemos neste trabalho está, em parte, em revelar o quanto o debate sobre a eutanásia é rico e complexo. A nosso ver, a ilegalidade desta prática em diversas sociedades contemporâneas (pelo menos no mundo ocidental) ainda tem por base, como fatores principais, a doutrina da sacralidade da vida, sobretudo em sua versão católica, e a morte como um tabu. Trata-se de uma sustentação um tanto quanto pobre, sobretudo se pensarmos que tal proibição afeta um grande número de pessoas, muitas vezes em um estado de sofrimento extremo. Independentemente da posição que se tenha sobre a legalização desta prática, assim, com certeza teríamos muito a ganhar com uma discussão mais rica sobre o problema, que envolva diversos setores da sociedade, não se restringindo apenas, assim, ao meio acadêmico. Neste trabalho procuramos apontar para alguns elementos relevantes desta discussão. 


\section{Referências}

COHEN, C. Os Animais Têm Direitos? In: GALVÃO, P. (ed) OS Animais Têm Direitos? Perspectivas e Argumentos. Lisboa: Dinalivro, 2010.

DWORKIN, R. O Domínio da Vida. São Paulo: Martins Fontes, 2009.

FOOT, P. Euthanasia. In: Virtues and Vices and Other Essays in Moral Philosophy. Oxford: Oxford University Press, 2002.

KANT, I. Fundamentação da Metafísica dos Costumes. Lisboa: Edições 70, 2011.

We Have No Duties to Animals. In: SHAFER-LANDAU, R. Ethical Theory - an anthology. Oxford: Wiley-Blackwell, 2013.

KRAUT, R. Two Conceptions of Happiness. The Philosophical Review, 88, no 2, p. 167197, 1979.

HILL, C. The Note. In: KUHSE, H; SINGER, P. (eds): Bioethics - an anthology. Oxford: Blackwell Publishing, 2006.

LORBER, J. Ethical issues in the management of myelomeningocele and hydrocefalus. Journal of the Royal College of Physicians of London, 10, 1, p. 47-60, 1975.

MCMAHAN, J. A Ética no Ato de Matar. Porto Alegre: Artmed Editora, 2011.

RAWLS, J. A Theory of Justice - revised edition. Cambridge: Harvard University Press, 1999.

Sagrada Congregação Para a Doutrina da Fé. Disponível em: http://www.vatican.va/ roman_curia/congregations/cfaith/index_po.htm. Acesso em: 16 jul. 2018.

SINGER, P. Ética Prática. São Paulo: Martins Fontes, 2002.

TAYLOR, C. As Fontes do Self. São Paulo: Loyola, 2010.

VELLEMAN, J. D. “A Right of Self-Termination?”. Ethics 109, pp. 338-74, 1999. 